\title{
ATIVIDADE MICROBIANA DO SOLO EM FUNÇÃO DO SISTEMA DE CULTIVO E INTEGRAÇÃO LAVOURA-PECUÁRIA
}

Rafael Barroca Silva', Thaís Araújo Correia', Fábio Fernando De Araújo², Paulo Claudeir Gomes da Silva ${ }^{2}$

${ }^{1}$ Discente do curso de Agronomia da Universidade do Oeste Paulista. ${ }^{2}$ Docente da Faculdade de Ciências Agrárias da Universidade do Oeste Paulista. E-mail: rafa_fusca64@hotmail.com

\section{RESUMO}

O modo de manejo e o sistema de plantio exercido em um solo podem influenciar as características microbiológicas deste. Este trabalho pretendeu avaliar parâmetros microbiológicos de solos submetidos a dois sistemas de plantio e a influência da integração lavoura-pecuária. 0 experimento foi conduzido em área experimental do Curso de Agronomia localizada no Campus II, da UNOESTE, em Presidente Prudente, SP. Foram avaliadas 8 faixas de solo cultivadas com milho, em sistema convencional e plantio direto, e consórcio ou não com Urochloa brizantha. O solo com plantio convencional obteve média de respiração microbiana $63,8 \%$ a mais que o solo em plantio direto. O consórcio com capim proporcionou mais respiração microbiana, em comparação ao cultivo sem consórcio. O mesmo aconteceu na atividade enzimática, onde a média foi $22 \%$ maior de atividade comparado ao cultivo de milho sozinho.

Palavras-chave: atividade microbiana; sistema de cultivo; integração lavoura-pecuária; milho; Urochloa brizantha cv MG-4

\section{INTRODUÇÃO}

Sabe-se que as características biológicas do solo, juntamente com as propriedades químicas e físicas, interferem ativamente na produtividade e qualidade de produtos agropecuários. Dentro das características biológicas do solo, um dos principais fatores é a atividade microbiana. Os microorganismos - principalmente fungos e bactérias - exercem um importante papel nas propriedades biológicas de um solo. As bactérias têm alta taxa de crescimento e uma boa capacidade de ciclagem de nutrientes. Existem exemplos de espécies que fixam o nitrogênio gasoso (N2), além de outras que têm outras funções variadas. Os fungos são todos heterótrofos, se alimentando de outros compostos orgânicos já formados, vivos ou mortos. Geralmente são aeróbios, e predominam em solos mais ácidos, com faixas de $\mathrm{pH}$ variando entre 3,0 a 9,0, dependendo da espécie. (BRANDÃO, 1992).

Há uma grande interação entre os microorganismos do solo. Essas interações podem ter significativa importância para processos bioquímicos, e representar aumento de produção agrícola. A vida microbiana do solo é influenciada, principalmente, por alguns fatores, como temperatura, $\mathrm{pH}$, luminosidade, salinidade, fontes de energia e substratos orgânicos, nutrientes e 
presença ou ausência de elementos tóxicos. (ARAÚJO et al, 2008). Os diferentes tipos de manejo exercido em um solo podem interferir nesses fatores, podendo alterar a população microbiana e sua atividade.

Atualmente, no Brasil, um conceito que vem sendo desenvolvido é a Integração LavouraPecuária. Pode-se definir como sendo uma integração de atividades agrícolas e pastoris conduzidas em uma mesma área, de modo que se tenham benefícios para os dois tipos de atividades. A ILP pode ser implantada com vários objetivos, como recuperação de pastagens degradadas e produção de alimentação animal. Além disso, o sistema pode contribuir para a melhoria das condições do solo, maior independência de insumos externos, diminuição de custos e diversificação da renda. (ALVARENGA \& NOCE, 2005).

O sistema plantio direto se difundiu largamente pelo Brasil nos últimos trinta anos, largamente aceito pelos agricultores, sendo um modo de uso do solo adaptável aos diferentes níveis tecnológicos e recursos financeiros das propriedades rurais. (Cruz et al, 2002). O sistema plantio direto, depois de implantado e conduzido adequadamente pode trazer melhorias para o solo e maiores produtividades.

\section{MATERIAIS E MÉTODOS}

O experimento foi conduzido em área experimental do Curso de Engenharia Agronômica localizada no Campus II, da Universidade do Oeste Paulista - UNOESTE, em Presidente Prudente, SP. O delineamento experimental foi feito em 8 faixas de aproximadamente $150 \mathrm{~m}$ de comprimento por $8 \mathrm{~m}$ de largura. A cultura instalada foi milho "safrinha", sendo que havia sorgo ou soja como cultura anterior. O cultivo das faixas foi intercalado entre milho sozinho e milho consorciado com capim da espécie Urochloa brizantha cv MG-4 (figura 1).

\begin{tabular}{|c|c|c|c|c|c|}
\hline \multirow{4}{*}{$\begin{array}{l}\text { PLANT IO } \\
\text { DIRET O }\end{array}$} & SORGO & $\theta$ & $\otimes$ & 8 & 8 \\
\hline & SOJA & $\theta$ & $\theta$ & $\otimes$ & $\Theta$ \\
\hline & SOJA & $\otimes$ & $\otimes$ & $\otimes$ & $(8)$ \\
\hline & SORGO & $\otimes$ & 8 & $\otimes$ & 8 \\
\hline \multirow{4}{*}{$\begin{array}{l}\text { PLANTIO } \\
\text { COMENCIONAL }\end{array}$} & sorgo & $\otimes$ & $\otimes$ & $\otimes$ & $\theta$ \\
\hline & SOJA & $\otimes$ & $\otimes$ & $\otimes$ & $\otimes$ \\
\hline & SOJA & $\otimes$ & 8 & 8 & 8 \\
\hline & SORGO & $\otimes$ & $\otimes$ & $\boldsymbol{\theta}$ & $\otimes$ \\
\hline
\end{tabular}

Figura 1. esquema do experimento. Os pontos indicados nas faixas indicam onde foram feitas as coletas. 
As plantas já estavam no início do estágio de maturação das espigas quando foi feita a coleta de solo. A coleta foi feita na profundidade de $0-20 \mathrm{~cm}$, em 4 pontos diferentes em cada faixa. (Figura 1). Em seguida, foram realizadas as análises de respiração microbiana e atividade enzimática.

Para a análise de respiração microbiana, foram colocados $50 \mathrm{~g}$ de solo de cada amostra em frascos herméticos, juntamente com um bécker contendo $40 \mathrm{ml}$ de solução de hidróxido de sódio $(\mathrm{NaOH})$. O branco da análise consiste em um frasco hermético com o bécker contendo solução de $\mathrm{NaOH}$, sem solo. Essa análise foi feita em duplicata. Fez-se a leitura da condutividade elétrica 24 horas após a montagem da análise, e calculadas as médias dos resultados para cada tratamento.

$\mathrm{Na}$ análise de atividade da enzima desidrogenase, foram usados 3 tubos de ensaio para cada amostra (um branco e uma duplicata), onde cada tubo recebeu $5 \mathrm{~g}$ de solo. No solo que serviu de branco, foi adicionado $1 \mathrm{ml}$ de solução de glicose $0,1 \%$ e $2 \mathrm{ml}$ de solução tampão tris $0,1 \mathrm{M}$ a pH 7,6 , enquanto que nos outros dois tubos adicionou-se $1 \mathrm{ml}$ de glicose $0,1 \%$ e $2 \mathrm{ml}$ de solução de tetrazólio $1 \%$. Os tubos foram agitados e incubados por 18 horas, e em seguida adicionados 9ml de metanol em todos os tubos, com posterior filtragem e leitura no espectrofotômetro ajustado a $530 \mathrm{~nm}$. Foi tirada uma média dos resultados das duplicatas de cada amostra.

\section{RESULTADOS E DISCUSSÃO}

Os resultados mostraram que os solos manejados no sistema plantio convencional tiveram uma média mais elevada de respiração microbiana quando comparados aos solos conduzidos no sistema plantio direto (figura 2). Uma possível explicação para esse fato é que o sistema convencional pode proporcionar mais aeração do solo durante revolvimento do solo, favorecendo a atividade microbiana. Em experimento realizado por Neves et al (2009), foi observado que o plantio direto, no primeiro ano, apresentou menores índices microbiológicos, que melhoraram a partir dos anos seguintes. A atividade enzimática, no entanto, mostrou um resultado contrário, apresentando maior média nos solos com plantio direto, com resultados $64 \%$ maiores do que no sistema convencional.

Quanto ao consórcio com Braquiária, os solos apresentaram médias de respiração microbiana $38 \%$ maiores do que os cultivados com milho solteiro (figura 2 ), nos dois sistemas de cultivo. Vale ressaltar que no plantio convencional o cultivo com braquiária teve médias $33 \%$ 
Encontro de Ensino, Pesquisa e Extensão, Presidente Prudente, 21 a 24 de outubro, 2013

maiores do que no cultivo de milho solteiro, enquanto que no sistema de plantio direto o acréscimo foi de $46 \%$.

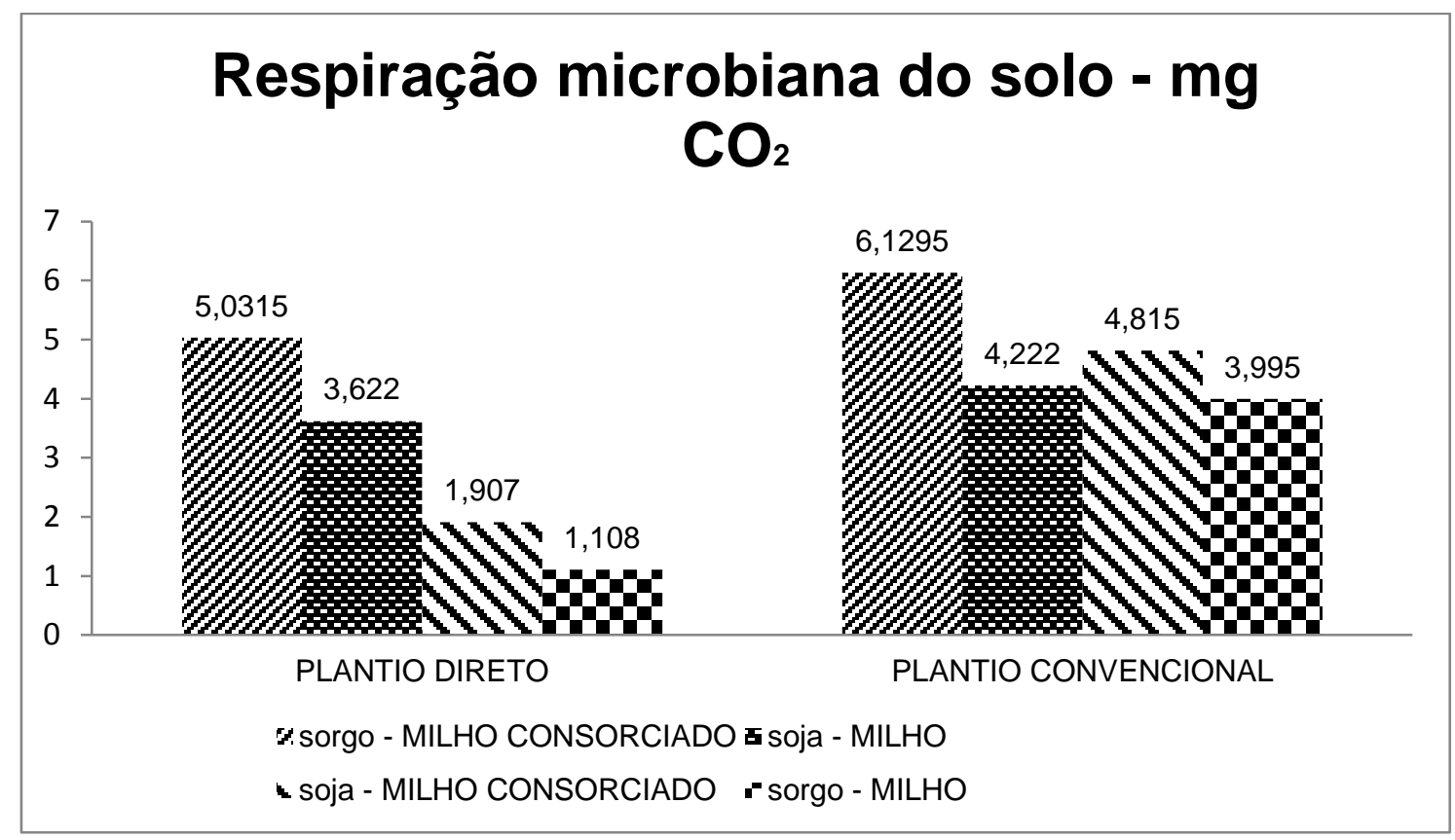

Figura 2. Valores médios de respiração microbiana (mg CO2) em diferentes sistemas de cultivo e consórcio ou não com Urochloa brizantha cv MG-4.

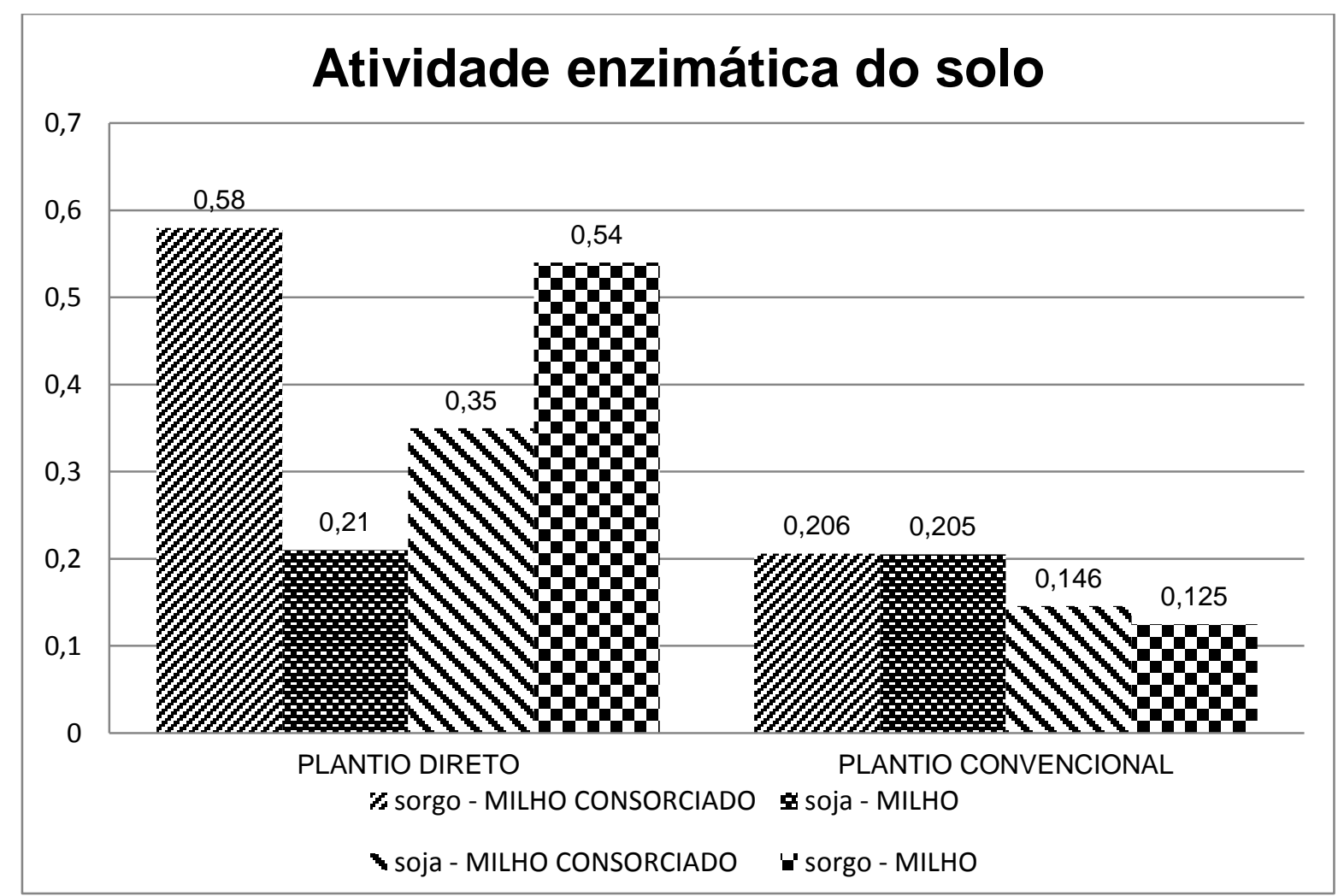

Figura 3. Atividade enzimática do solo (desidrogenase), em diferentes sistemas de cultivo e consórcio ou não com Urochloa brizantha cv MG-4 


\section{CONCLUSÃO}

Os solos manejados no sistema plantio direto apresentaram valores de atividade enzimática maiores do que os solos em plantio convencional. Entretanto, a respiração do solo foi maior no sistema convencional.

O consórcio de milho com a braquiária proporcionou melhores índices de respiração microbiana do solo. O cultivo de capim com o milho pode ser usado com benefícios para o solo dentro da Integração Lavoura-Pecuária.

\section{REFERÊNCIAS}

ALVARENGA, R. C., NOCE, M. A. Integração lavoura e pecuária - Sete Lagoas: Embrapa Milho e Sorgo, 2005. Disponível em http://www.infoteca.cnptia.embrapa.br/handle/doc/489736

ARAÚJO, A. S. F.Ecologia Microbiana do Solo. In: ARAÚJO et al. Matéria Orgânica e Organismos do solo. Teresina: Universidade Federal do Piauí, 2008. Capítulo 02.

BRANDÃO, E. M., Os componentes da comunidade microbiana do solo. In: CARDOSO, E. J. B. N. et al. Microbiologia do Solo. Campinas, Sociedade Brasileira de Ciência do Solo, 1992. Capítulo 01.

CRUZ, J. C. et al, CULTIVO DO MILHO - Sistema Plantio Direto, EMBRAPA, Comunicado Técnico $n^{\circ}$ 51, 2002. Disponível em http://www.infoteca.cnptia.embrapa.br/handle/doc/487009

NEVES, Cláudia Milene Nascente et al . Indicadores biológicos da qualidade do solo em sistema agrossilvopastoril no noroeste do estado de Minas Gerais. Ciênc. agrotec., Lavras, v. 33, n. 1, fev. 2009 . Disponível em <http://www.scielo.br/scielo.php?script=sci_arttext\&pid=S141370542009000100015\&lng=pt\&nrm=iso>. acessos em 14 ago. 2013.

PEREIRA NETO, Osvaldo C. et al . Análise do tempo de consolidação do sistema de plantio direto. Rev. bras. eng. agríc. ambient., Campina Grande, v. 11, n. 5, out. 2007 . Disponível em $<$ http://www.scielo.br/scielo.php?script=sci_arttext\&pid=S1415-

43662007000500007\&lng=pt\&nrm=iso>. 